OPEN ACCES

Nano Biomed Eng

ISSN 2150-5578 http://nanobe.org

\title{
Biogenic Synthesis of Antifungal Silver Nanoparticles Using Aqueous Stem Extract of Banana
}

\author{
Jayabrata Das, Palaniyandi Velusamy* \\ ${ }^{1}$ Department of Biotechnology, School of Bioengineering, SRM University, Chennai 603203, India \\ * Corresponding author: velusamy.p@ktr.srmuniv.ac.in \\ Tel/fax.: + 91-442357824
}

\begin{abstract}
The present study reports the synthesis of silver nanoparticles (AgNPs) from silver precursor using banana stem extract (BSE) as a plant biomaterial. Biologically synthesized AgNPs were observed at $425 \mathrm{~nm}$ with particle size ranges from $75.50 \mathrm{~nm}$ to $1.22 \mu \mathrm{m}$ of truncated octahedron, rhombdodecahedron, cubic, octahedron and octagon structures. The presence of water-soluble organic compounds such as flavanones, polyphenols etc. in the BSE was identified by FTIR which were found to be responsible for the reduction of $\mathrm{Ag}^{+}$ions to AgNPs. The EDX analysis of the nanoparticles dispersion, using a range of $2-4 \mathrm{keV}$, confirmed the presence of elemental silver, with no other impurity peaks detected. In addition, the characterised AgNPs have the potential for various medical and industrial applications. The results showed that fungal susceptibility to AgNPs is different for each fungus.
\end{abstract}

Keywords: Biomaterial, Silver nanoparticles, FE-SEM, Fungal susceptibility

Citation: J. Das and P. Velusamy. Biogenic Synthesis of Antifungal Silver Nanoparticles Using Aqueous Stem Extract of Banana. Nano Biomed. Eng. 2013, 5(1), 34-38.

DOI: $10.5101 /$ nbe.v5i1.p34-38.

\section{Introduction}

In the past decade, biological systems of microbial and plant origin have provided eco-friendly methods of nanoparticle (NP) synthesis [1-4]. Bio-inspired techniques often lead to the fabrication of nanostructures that are uniform in size and shape [5]. Compare to microbes, plant mediated biological synthesis of metal nanoparticles provides a promising eco-friendly alternative for realizing large quantities of nanomaterials, as it does not involve harmful chemicals, eliminates the elaborate process of maintaining cell cultures, easy to recovery of products and also exhibits a dual nature such as capping and reducing at one go $[6,7]$. Thus phyto-inspired synthetic procedures have become popular and a search for plant extracts with reducing (anti-oxidant) properties mediating such reactions continues [8]. Gardea-Torresdey et al. initially reported the possibility of using plant materials for the synthesis of nano-scale metals $[9,10]$. Later, the bioreduction of various metals to nano-size of various shapes, capable of meeting the requirements of diverse industrial applications, was extensively studied [1113]. In addition, Huang et al. demonstrated the prospect of using sun dried, Cinnamon camphora leaf for the synthesis of the nano-sized Ag and Au noble metals at ambient conditions, without any additive protecting nanoparticles from aggregating, template-shaping nanoparticles or accelerants like ammonia [14]. Recently, plant materials such leaf [15], fruit [16], bark [17], fruit peels [18], root [19], leaf [20], and callus [21] have been studied in this direction more exclusively. The methods using plant extracts involve phytochemicals such as terpenoids, flavonoids, phenol derivatives, plant enzymes (hydrogenases, reductases) and their derivatives, di-hydric phenols and so on, act as a reductant in the presence of metal salt. The above evidences state the dependency of source, structure and type of phenolic phytochemical on different sized nanoparticles formation [22].

In this paper, we discuss the biosynthesis of silver nanoparticles (AgNPs) using commercially economic and abundantly available banana stem as the biomaterial. Phytochemicals studies on banana stem extract (BSE) showed the presence of flavonoids, polyphenols and their derivatives which are largely responsible for antioxidant and free radical-scavenging properties [23]. However, 
till date, there have been no reports on the synthesis of AgNPs using BSE. The formation and growth of the nanoparticles was monitored with the help of absorption spectroscopy, while their shape, size and morphologies were determined by scanning electron microscopy (SEM).

\section{Material and methods}

\subsection{Preparation of aqueous BSE}

The healthy stem of banana was collected from the local market at Tambaram, Chennai, washed thoroughly to remove any impurities. Aqueous BSE was prepared by boiling $10 \mathrm{~g}$ of freshly cut stem pieces in $100 \mathrm{~mL}$ of distilled water at $60{ }^{\circ} \mathrm{C}$ for $8 \mathrm{~min}$. The extracts were filtered through a nylon mesh $(0.2 \mu \mathrm{m})$ and followed by Whatman No. 1 filter paper. The filtered extract was stored at $4{ }^{\circ} \mathrm{C}$ for further studies.

\subsection{Synthesis of AgNPs}

Silver nitrate $\left(\mathrm{AgNO}_{3}\right)$ was purchased from Hi Media Lab. Pvt. Ltd., India. In a typical reaction procedure, 0.250 $\mathrm{mL}$ of stem extract was added to $9 \mathrm{~mL}$ of $2 \mathrm{mM}$ aqueous silver nitrate solution, the mixture was heated at $60{ }^{\circ} \mathrm{C}$ for $20 \mathrm{~min}$ and the resulting solution became brown in colour after $30 \mathrm{~min}$. The aqueous $\mathrm{BSE}$ and $\mathrm{AgNO}_{3}$ solution were used as controls throughout the experiment.

\subsection{UV-vis spectra analysis}

The biosynthesis of AgNPs was monitored periodically in a UV-vis spectrophotometer. For the analysis, $1 \mathrm{~mL}$ of the sample in a cuvette and was diluted to $2 \mathrm{~mL}$ with deionized water. The UV-vis spectra of the resulting diluents were monitored as a function of reaction time at a resolution of $1 \mathrm{~nm}$ from 300 to $800 \mathrm{~nm}$. UV-vis spectra showed strong Surface Plasmon Resonance band at 425 $\mathrm{nm}$ and thus indicating the formation of AgNPs.

\subsection{Characterization of AgNPs}

The AgNPs formed in the reaction solution were recovered by centrifugation at 18,000 rpm for $20 \mathrm{~min}$, and their pellets were redispersed in sterile distilled water to get rid of any uncoordinated biological molecules. The centrifugation and redispersion in sterile distilled water was repeated three times to ensure better separation of free entities from the AgNPs. Finally purified suspension of the AgNPs was dried in hot air oven at $250{ }^{\circ} \mathrm{C}$ for $2 \mathrm{~h}$ and used for FE-SEM, EDS and XRD studies. To identify the biomolecules present in the BSE and within the synthesized AgNPs, lyophilized sample of the same were subjected to FTIR spectroscopy in the diffuse reflectance mode at a resolution of $4 \mathrm{~cm}^{-1}$ in $\mathrm{KBr}$ pellets.

\subsection{Antifungal activity of biosynthesized AgNPs}

Various pathogenic fungal strains of Candida albicans, Aspergillus niger and Alternaria alternata were obtained from SRM medical college hospital and research centre, Kattankulathur, Chennai. The antifungal activity of AgNPs was investigated by the standard Kirby-Bauer disc diffusion assay method against the fungal strain. The fungal suspension of $48 \mathrm{~h}$ grown strains was swabbed on Potato Dextrose Agar (PDA) plates using sterile cotton swab. Double sterilized paper disc (6 $\mathrm{mm}$ diameter) was placed on PDA plates and then the AgNPs (25, 50, 75 and $100 \mu \mathrm{g} \mathrm{mL}^{-1}$ ) concentration was loaded into each disc. The plates were incubated at $28{ }^{\circ} \mathrm{C}$ for $48 \mathrm{~h}$. After the incubation period, the zone of inhibition was determined by measuring the diameter by using Hi Media antibiotic zone scale.

\section{Results and discussion}

AgNPs can form within $30 \mathrm{~min}$ and spectra of reaction solutions were recorded after $0,1,3,5$ and $7 \mathrm{~h}$ consecutively. The spectra showed that there was an increase in the intensity of absorbance as the concentration of AgNPs increased with the reaction time (Fig. 1a). The strong resonance centered at 425 $\mathrm{nm}$ was monitored; it might be due to the excitation of longitudinal plasmon vibrations of the anisotropic AgNPs present in the solution. The results were in accordance with the report of Naik et al. [24]. The BSE without addition of the $\mathrm{AgNO}_{3}$ was used as a control and showed a peak at 220 and $280 \mathrm{~nm}$ (Fig. 1b). The strong absorption peak located at $220 \mathrm{~nm}$ is due to the reducing protein molecules present in the BSE and at $280 \mathrm{~nm}$ indicated the presence of tyrosine, tryptophan and/or phenylalanine residues in the proteins which are known to interact with silver ions, respectively [25].

The major factor responsible for the biological reduction of $\mathrm{Ag}^{+}$to $\mathrm{Ag}$ present in the $\mathrm{BSE}$ was identified using FTIR spectroscopy. The IR spectrum of BSE alone showed the presence of distinct peaks in the range of 1067, 1225, 1381, 1633, 2923 and $3416 \mathrm{~cm}^{-1}$ (Fig. 2a). The strong intense peak located at around $1381 \mathrm{~cm}^{-1}$ could be assigned for carboxyl groups. The medium bands appeared at $1067 \mathrm{~cm}^{-1}$ and $1633 \mathrm{~cm}^{-1}$ are due to fatty acid and flavanone respectively [26]. The weak absorption peaks centered at 1225 and $2923 \mathrm{~cm}^{-1}$ are attributed to amide band of proteins and carboxylic acids $[27,28]$ present in the stem extract. In addition, there

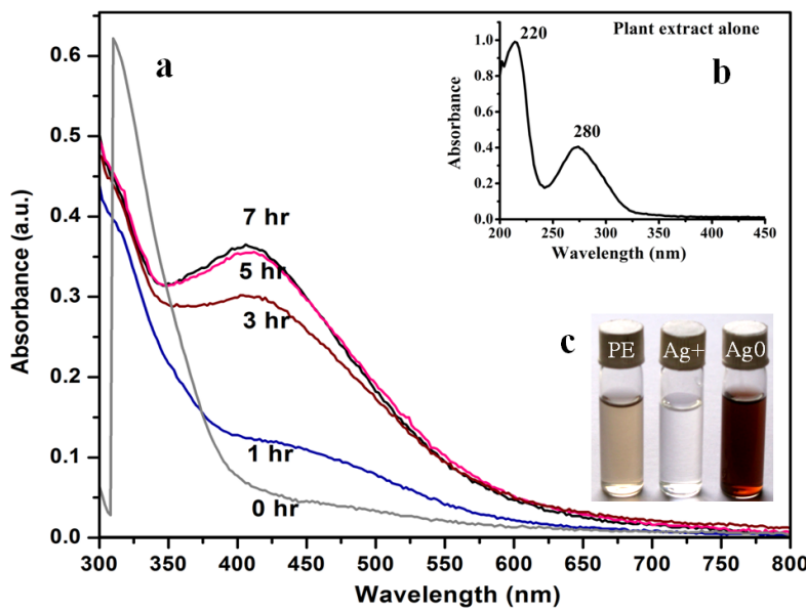

Fig. 1 UV-Vis spectra of (a) leaf extract as a function of reaction time (b) BSE alone and (c) showing changes in color after adding $\mathrm{AgNO}_{3}$, before and after reaction. 
reflect the effects due to experimental conditions on the nucleation and growth of the crystal nuclei [31].

The size and morphology of the AgNPs were characterized by FE-SEM. Fig. 4 images showed variable size ranging from $75.50 \mathrm{~nm}$ to $1.22 \mu \mathrm{m}$ of truncated octahedron, rhomb-dodecahedron, cubic, octahedron and octagon structure of AgNPs indicating that AgNPs have a high tendency to self-assemble into two- or threedimentional super lattice structures. Further close view of FE-SEM images showed the superlattice structures of AgNPs; irregularly shaped 3D superlattice structures with clearly defined edges were observed, and the domain size of the superlattice structures could reach up to several micrometers. According to the Wolff's rule, the crystals try to assume a shape of least surface free energy at thermodynamic equilibrium. Therefore, formations of truncated octahedron, rhomb-dodecahedron, cubic, octahedron and octagon structures are thermodynamically favoured at nucleation stage and initial growth stage when the particle sizes are not very large [32-34]. EDX spectroscopy results confirmed the significant presence of metal silver. The optical absorption peak was observed approximately at $3 \mathrm{keV}$ shown in Fig. 5, which is typical for the absorption of metallic silver nanocrystallites due to Surface Plasmon Resonance. Along with this, weak chloride peaks due to the presence of chloride ions that might present in the plant extract were also found.

AgNPs are known to be a highly reactive species due to their extremely large surface area and can exhibit potent antimicrobial activity. A similar observation was made here with the AgNPs produced by BSE to have
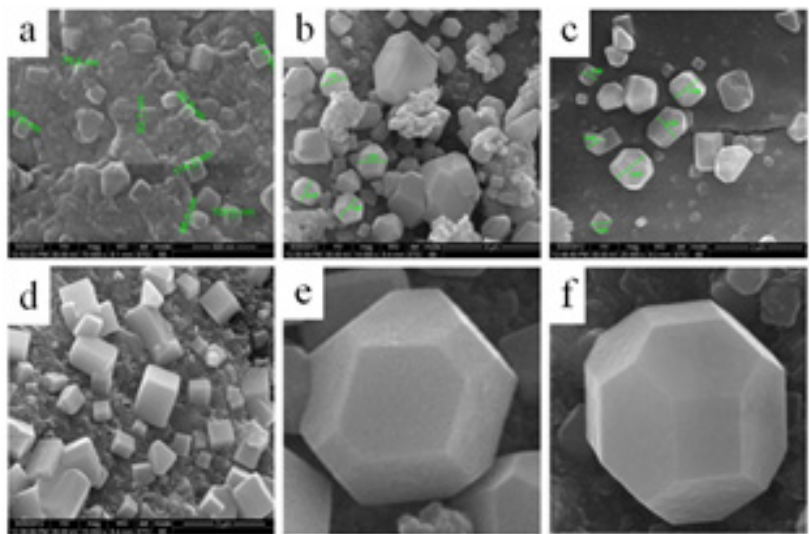

AgNPs using BSE.

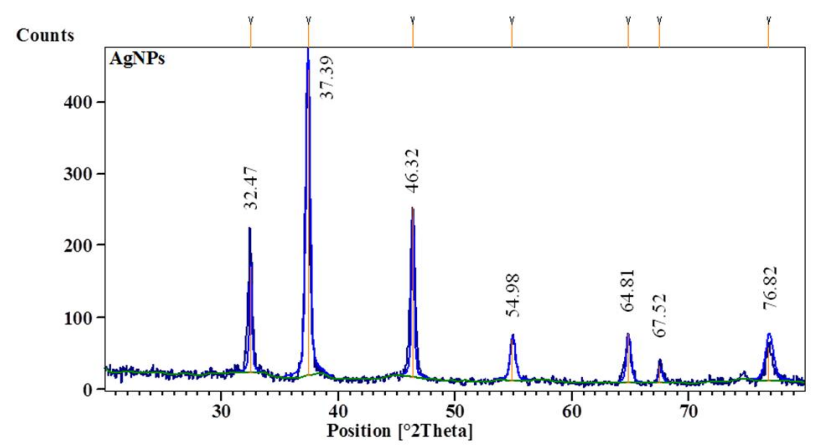

Fig. 3 XRD pattern of biosynthesized AgNPs using BSE.
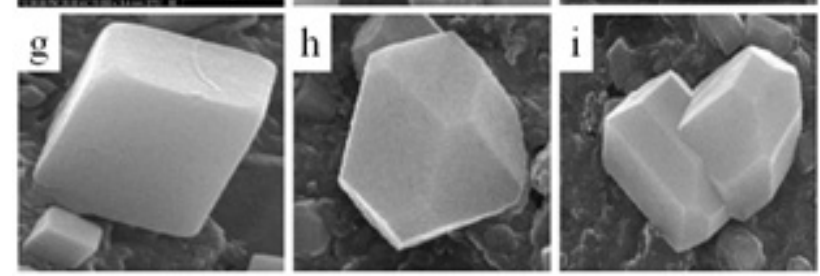

Fig. 4 FE-SEM images of (a, b, c, and d) biosynthesized AgNPs at various magnification, (e) truncated octahedron, (f) rhombdodecahedron, (g) cubic, (h) octahedron, and (i) octagon structure of AgNPs. 


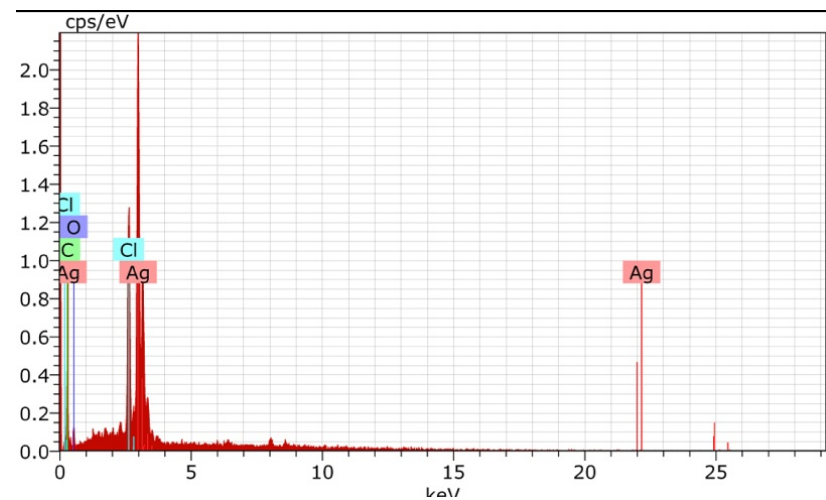

Fig. 5 EDX spectrum of synthesized AgNPs.

antifungal activity against the pathogenic fungi of $C$. albicans, A. niger and A. alternata. The present result showed that the antifungal activity was more pronounced to $A$. niger than $C$. albicans and A. alternata and the maximum zone of inhibition with diameter of $13.30 \mathrm{~mm}$ was recorded in respect of $A$. niger [Fig. 6]. Antifungal activity however, was not significantly observed against C. albicans and A. alternata when treated with low $(25$ and $50 \mu \mathrm{g} \mathrm{mL}^{-1}$ ) concentration of AgNPs. According to Dorau et al. the antifungal activity is due to the formation of insoluble compounds by inactivation of sulfhydryl groups in the fungal cell wall and disruption of membrane bound enzymes and lipids which causes cell lysis [35]. Previously, Kim et al. revealed that the interaction between nanosilver and the membrane structure of $C$. albicans cells during nano-Ag exposure results in changes in the membranes of $C$. albicans, which can be observed as the "pits" on the membrane surfaces and finally the formation of pores subsequent cell death [36].

\section{Conclusion}

Biosynthesis of AgNps using BSE was demonstrated to be a simple, low-cost and non-toxic method. The study proved that the stem extract is capable of producing

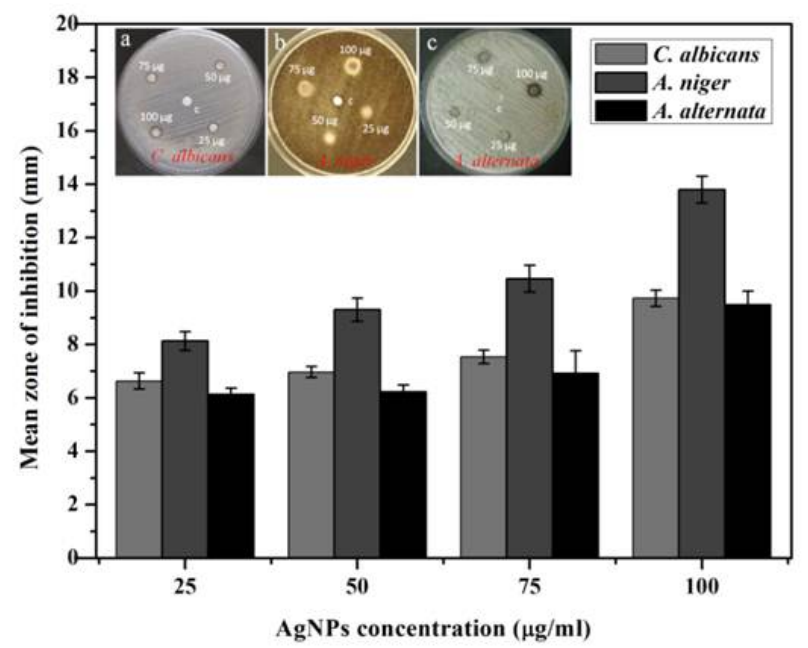

Fig. 6 Antifungal activities of AgNPs against $C$. albicans, A. niger and $A$. alternata. truncated octahedron, rhomb-dodecahedron, cubic, octahedron, and octagon structure of AgNPs at $60{ }^{\circ} \mathrm{C}$ without using any templates, additives or accelerants. Phytochemical such as flavanones and polyphenols present in the plant material were mainly responsible for the reduction of $\mathrm{Ag}^{+}$ions to nanosized silver particles. The nanoparticles are found to be highly crystalline as evidenced by the peaks in the XRD pattern corresponding to Bragg reflections from the (111), (200), (220), (311) and (222) planes of the fcc structure. The antifungal activity of biologically synthesized AgNPs was evaluated against $C$. albicans, A. niger and A. alternata showing effective antifungal activity.

\section{Acknowledgements}

The authors convey their thanks to SRM University, Chennai, for providing laboratory facilities. Thanks are also due to Dean, School of Bioengineering, SRM University, Chennai for providing valuable discussion and facilities.

\section{References}

1 Mandal D., Bolander M.E., Mukhopadhyay D., Sarkar D., Mukherjee P. The use of microorganisms for the formation of metal nanoparticles and their application. Appl. Microbiol. Biotechnol. 2006; 69:485-492.

2 Thakkar K.N., Mhatre S.S., Parikh R.Y. Biological synthesis of metallic nanoparticles. Nanomed. Nanotechnol. Biol. Med. 2010; 6: 257-262.

3 Narayan K.B., Sakthivel N. Biological synthesis of metal nanoparticles by microbes. Adv. Colloid Interface Sci. 2010; 156: 1-13.

4 Vijayraj D., Anarkali J., Rajathi K., Sridhar S. A facile green synthesis of silver nanoparticles using the medicinal plant Leucas aspera and their antibacterial activity. Nano Biomed. Eng. 2012; 4: 95-98.

5 Wu L.Q., Payne G.F. Biofabrication: using biological materials and biocatalysts to construct nanostructured assemblies. Trends Biotechnol. 2004; 22: 593-599.

6 Saxena A., Tripathi R.M., Zafar F., Singh P. Green synthesis of silver nanoparticles using aqueous solution of Ficus benghalensis leaf extract and characterization of their antibacterial activity. Mater. Lett. 2012; 67: 91-94.

7 Varma R.S. Greener approach to nanomaterials and their sustainable applications. Curr. Opin. Chem. Eng. 2012; 1: 123-128.

8 Rao A., Mahajan K., Bankar A., Srikanth R., Kumar A.R., Gosavi S., Zinjarde S. Facile synthesis of size-tunable gold nanoparticles by pomegranate (Punica granatum) leaf extract: Applications in arsenate sensing. Mater. Res. Bull. 2013; 48: 1166-1173.

9 Gardea-Torresdey J.L., Parsons J.G., Dokken K., Peralta-Videa J.R., Troiani H., Santiago P., Jose-Yacaman M. Formation and growth of Au nanoparticles inside live alfalfa plants. Nano. Lett. 2002; 2:397-401.

10 Gardea-Torresdey J.L., Gomez E., Peralta-Videa J., Parsons J.G., Troiani H.E., Jose-Yacaman M. Alfalfa Sprouts: a natural source for the synthesis of silver nanoparticles. Langmuir 2003; 1: 1357-1361.

11 Shankar S.S., Ahmad A., Sastry M. Geranium leaf assisted biosynthesis of silver nanoparticles. Biotechnol. Prog. 2003; 19: 1627-1631.

12 Shankar S.S., Rai A., Ankamwar B., Singh A., Ahmad A., Sastry M. Biological synthesis of triangular gold nanoprisms. Nat. Mater. 2004; 3: 482-488.

13 Rai A., Singh A., Ahmad A., Sastry M. Role of halide ions and temperature on the morphology of biologically synthesized gold nanotriangles. Langmuir 2006; 2: 736-741.

14 Huang J., Li Q., Sun D., Lu Y., Su Y., Yang X., Wang H., Wang Y., Shao W., He N., Hong J., Chen C. Biosynthesis of silver and gold nanoparticles by novel sundried Cinnanonum camphora leaf. Nanotechnology 2007; 18: 105104-115114.

15 Das J., Das M.P., Velusamy P. Sesbania grandiflora leaf extract mediated green synthesis of antibacterial silver nanoparticles against 
selected human pathogens. Spectrochim. Acta A 2013; 104: 265-270.

16 Gopinath V., Ali D.M., Priyadarshini S., Priyadharsshini N.M., Thajuddin N., Velusamy P. Biosynthesis of silver nanoparticles from Tribulus terrestris and its antimicrobial activity: A novel biological approach. Colloids Surf. B 2012; 96: 69-74.

17 Sathishkumar M., Sneha K., Won S.W., Cho C.W., Kim S., Yun Y.S Cinnamon zeylanicum bark extract and powder mediated green synthesis of nano-crystalline silver particles and its bactericidal activity. Colloids Surf. B 2009; 73: 332-338.

18 Kaviya S., Santhanalakshmi J., Viswanathan B., Muthumary J., Srinivasan K. Biosynthesis of silver nanoparticles using citrus sinensispeel extract and its antibacterial activity. Colloids Surf. A 2011; 79: 594-598.

19 Ahmad N., Sharma S., Alam M.K., Singh V.N., Shamsi S.F., Mehta B.R., Fatma A. Rapid synthesis of silver nanoparticles using dried medicinal plant of basil. Colloids Surf. B 2010; 81: 81-86.

20 Gopinath V., Priyadarshini S., Priyadharsshini N.M., Pandian K., Velusamy P. Biogenic synthesis of antibacterial silver chloride nanoparticles using leaf extracts of Cissus quadrangularis Linn. Mater. Lett. 2013; 91: 224-227.

21 Nabikhan A., Kandasamy K., Raj A., Alikunhi N.M. Synthesis of antimicrobial silver nanoparticles by callus and leaf extracts from saltmarsh plant, Sesuvium portulacastrum L. Colloids Surf. B 2010; 79: 488-493.

22 Rao K.J., Puria S. Green synthesis of silver nanoparticles from aqueous Aegle marmelos leaf extract. Mater. Res. Bull.2013; 48: 628-634.

23 Aziz N.A.A., Ho L.H., Azahari B., Bhat R., Cheng L.H., Ibrahim M.N.M. Chemical and functional properties of the native banana (Musa acuminata $\times$ balbisiana Colla $c v$. Awak) pseudo-stem and pseudo-stem tender core flours. Food Chem. 2011; 128: 748-753.

24 Naik R.R., Stringer S.J., Agarwal G., Jones S.E., Stone M.O. Biomimetic synthesis and patterning of silver nanoparticles. Nat. Mater. 2002; 1: 169-172.

25 Gruen L.C. Interaction of Amino Acids with Silver(I) Ions. Biochim. Biophys. Acta 1975; 368: 270-274.
26 Rajakumar G., Abdul Rahuman A. Larvicidal activity of synthesized silver nanoparticles using Eclipta prostrata leaf extract against filariasis and malaria vectors. Acta Trop. 2011; 118: 196-203.

27 Song J.Y., Jang H.K., Kim B.S. Biological synthesis of gold nanoparticle using Magnolia kobus and Diopyros kaki leaf extracts. Process Biochem. 2009; 44: 1133-1138.

28 Mallikarjuna K., Sushma N.J., Narasimha G., Manoj L., Raju B.D.P. Phytochemical fabrication and characterization of silver nanoparticle by using Pepper leaf broth. Arab. J. Chem. 2012;doi.org/10.1016/ j.arabjc.2012.04.001.

29 Shankar S.S., Ahmad A., Parischa R., Sastry M. Bioreduction of chloroaurate ions by geranium leaves and its endophytic fungus yields gold nanoparticles of different shapes. J. Mater. Chem. 2003; 13: 1822-1826.

30 Prathna T.C., Chandrasekaran N., Raichur A.M., Mukherjee A. Biomimetic synthesis of silver nanoparticles by Citrus limon (lemon) aqueous extract and theoretical prediction of particle size. Colloids Surf. B 2011; 82: 152-159.

31 Becheri A., Dürr M., Nostro P.L., Baglioni P. Synthesis and characterization of zinc oxide nanoparticles: application to textiles as UV-absorbers. J. Nanopart. Res. 2008; 10: 679-689.

32 Koga K., Sugawara K. Population statistics of gold nanoparticle morphologies: direct determination by HREM observations. Surf. Sci. 2003; 529: 23-35.

33 Baletto F., Ferrando R. Structural properties of nanoclusters: Energetic, thermodynamic, and kinetic effects. Rev. Mod. Phys. 2005; 77: 371-423.

34 Barnard A.S. One-to-one comparison of sunscreen efficacy, aesthetics and potential nanotoxicity. J. Phys. Chem. B 2006;110:24498-24504.

35 An investigation into the potential of ionic silver as a wood preservative, in: B. Dorau, R. Arango, F. Green III (Eds.), Proceedings of the 2nd Wood-Frame Housing Durability and Disaster Issues Conference, Forest Products Society, Las Vegas, NV, October 4-6, 2004; 133-145.

36 Kim K.J., Sung W.S., Suh B.K., Moon S.K., Choi J.S., Kim J.G., Lee D.G. Antifungal activity and mode of action of silver nanoparticles on Candida albicans. BioMetals 2009; 22: 235-242.

Copyright:(c) 2013 J. Das and P. Velusamy. This is an openaccess article distributed under the terms of the Creative Commons Attribution License, which permits unrestricted use, distribution, and reproduction in any medium, provided the original author and source are credited. 